\title{
Association of heat shock proteins with all-cause mortality
}

\author{
L. Broer • E. W. Demerath • M. E. Garcia • \\ G. Homuth • R. C. Kaplan • K. L. Lunetta • \\ T. Tanaka • G. J. Tranah $\cdot$ S. Walter • \\ A. M. Arnold • G. Atzmon • T. B. Harris • \\ W. Hoffmann • D. Karasik • D. P. Kiel • T. Kocher • \\ L. J. Launer • K. K. Lohman • J. I. Rotter • \\ H. Tiemeier • A. G. Uitterlinden • \\ H. Wallaschofski • S. Bandinelli • M. Dörr • \\ L. Ferrucci • N. Franceschini • V. Gudnason • \\ A. Hofman • Y. Liu • J. M. Murabito • \\ A. B. Newman • B. A. Oostra • B. M. Psaty • \\ A. V. Smith • C. M. van Duijn
}

Received: 16 February 2012 / Accepted: 17 April 2012 / Published online: 4 May 2012

(C) The Author(s) 2012. This article is published with open access at Springerlink.com

\begin{abstract}
Experimental mild heat shock is widely known as an intervention that results in extended longevity in various models along the evolutionary lineage. Heat shock proteins (HSPs) are highly upregulated
\end{abstract}

Electronic supplementary material The online version of this article (doi:10.1007/s11357-012-9417-7) contains

supplementary material, which is available to authorized users.

L. Broer $\cdot$ H. Tiemeier · A. G. Uitterlinden · A. Hofman •

C. M. van Duijn $(\bowtie)$

Department of Epidemiology, Erasmus Medical Center, Dr. Molewaterplein 50, PO-Box 2040, 3000 CARotterdam, The Netherlands

e-mail: c.vanduijn@erasmusmc.nl

L. Broer $\cdot$ H. Tiemeier $\cdot$ C. M. van Duijn

Netherlands Consortium of Healthy Aging,

Rotterdam, The Netherlands

E. W. Demerath

Division of Epidemiology and Community Health, School of Public Health, University of Minnesota,

Minneapolis, MN, USA

M. E. Garcia • T. B. Harris • L. J. Launer

Laboratory of Epidemiology, Demography, and Biometry, National Institute on Aging, National Institutes of Health, Bethesda, MD, USA immediately after a heat shock. The elevation in HSP levels was shown to inhibit stress-mediated cell death, and recent experiments indicate a highly versatile role for these proteins as inhibitors of programmed cell

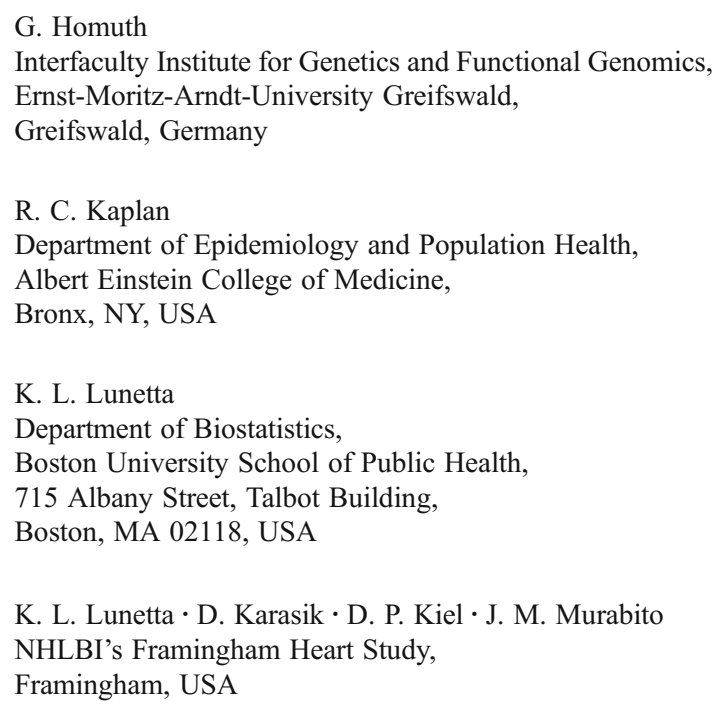

K. L. Lunetta • D. Karasik • D. P. Kiel • J. M. Murabito NHLBI's Framingham Heart Study,

Framingham, USA 
death. In this study, we examined common genetic variations in 31 genes encoding all members of the HSP70, small HSP, and heat shock factor (HSF) families for their association with all-cause mortality. Our discovery cohort was the Rotterdam study (RS1) containing 5,974 participants aged 55 years and older $(3,174$ deaths). We assessed 4,430 single nucleotide polymorphisms (SNPs) using the HumanHap550K Genotyping BeadChip from Illumina. After adjusting for multiple testing by permutation analysis, three SNPs showed evidence for association with all-cause mortality in RS1. These findings were followed in eight independent population-based cohorts, leading to a total of 25,007 participants $(8,444$ deaths). In the replication phase, only HSF2 (rs 1416733) remained significantly associated with all-cause mortality. Rs 1416733 is a known ciseQTL for $H S F 2$. Our findings suggest a role of $H S F 2$ in all-cause mortality.

Keywords Heat shock proteins · HEAT shock factor $2 \cdot$ All-cause mortality

T. Tanaka $\cdot$ L. Ferrucci

Clinical Research Branch, National Institute on Aging,

Baltimore, MD, USA

G. J. Tranah

California Pacific Medical Center,

San Francisco, CA, USA

\section{S. Walter}

Department of Society, Human Development, and Health, Harvard School of Public Health,

677 Huntington Avenue,

Boston, MA 02115, USA

A. M. Arnold

Department of Biostatistics, University of Washington,

Seattle, WA, USA

G. Atzmon

Institute for Aging Research and the Diabetes Research

Center, Albert Einstein College of Medicine,

Bronx, NY, USA

\section{G. Atzmon}

Department of Medicine,

Albert Einstein College of Medicine,

Bronx, NY, USA

G. Atzmon

Department of Genetics,

Albert Einstein College of Medicine,

Bronx, NY, USA

\section{Introduction}

Experimental mild heat shock is widely known as an intervention that results in extended longevity (Cypser and Johnson 2001). Brief exposure to elevated heat resulted in a $15 \%$ increase in the mean life span of Caenorhabditis elegans, compared to non heat-shocked controls (Cypser and Johnson 2001; Cypser and Johnson 2002; Lithgow et al. 1995). Similar effects have also been seen in Drosophila melanogaster (Hercus et al. 2003; Le Bourg et al. 2001), in yeast (Shama et al. 1998), and in cultured human cells (Rattan 1998). In the early 1960s, a group of proteins, now known as heat shock proteins (HSPs) were discovered, which were highly upregulated immediately after a heat shock (Ritossa 1962, 1996). Whether HSPs are responsible for longevity is still under debate, as their levels are only elevated for a short period of time after a heat shock (Link et al. 1999). However, the elevation in HSP levels during the heat shock response was shown to inhibit stress-mediated cell death, and recent experiments

\section{W. Hoffmann}

Institute of Community Medicine,

Ernst-Moritz-Arndt-University Greifswald,

Greifswald, Germany

D. Karasik · D. P. Kiel

Hebrew Senior Life Institute for Aging Research and Harvard Medical School,

Boston, MA, USA

T. Kocher

Dental School, Ernst-Moritz-Arndt-University Greifswald, Greifswald, Germany

K. K. Lohman

Sticht Center on Aging,

Wake Forest University School of Medicine,

Winston-Salem, NC, USA

\section{J. I. Rotter}

Medical Genetics Institute, Cedars-Sinai Medical Center, Los Angeles, CA, USA

H. Tiemeier

Department of Psychiatry, Erasmus Medical Center,

Rotterdam, The Netherlands
A. G. Uitterlinden
Department of Internal Medicine, Erasmus Medical Center, Rotterdam, The Netherlands 
indicate a highly versatile role for these proteins as inhibitors of programmed cell death (Garrido et al. 2006).

HSPs can be subdivided in several smaller families, including HSP90, HSP70, HSP60, HSP40, small HSP (sHSP), and HSP10 (Kampinga et al. 2009). From these families, HSP70 and SHSPs show an association with longevity. In C. elegans, extra copies of a homolog of HSPA9 (member of HSP70), otherwise known as mortalin, extended life span up to $45 \%$ (Yokoyama et al. 2002). In humans, decreased serum levels of HSP70 have been associated with exceptional longevity (95+) (Terry et al. 2006). However, the same study evaluated two single nucleotide polymorphisms (SNPs) in HSPA1A and HSPA1B which were not found to be associated to exceptional longevity (Terry et al. 2006).

The over-expression of members of the sHSP family has been shown to extend life of $C$. elegans and $D$. melanogaster by up to $32 \%$ (Morrow et al. 2004b; Walker et al. 2001). Conversely, the absence of expression of a sHSP member decreases lifespan of $D$. melanogaster by $40 \%$ (Morrow et al. 2004a).

HSP expression is regulated by a group of transcription factors known as heat shock factors (HSFs), of which HSF1 is considered to be the master-switch of HSP expression (Akerfelt et al. 2010). Strong

$\overline{\text { H. Wallaschofski }}$

Institute of Clinical Chemistry and Laboratory Medicine, University Medicine Greifswald,

Ernst-Moritz-Arndt-University Greifswald,

Greifswald, Germany

\section{S. Bandinelli}

Geriatric Unit, Azienda Sanitaria Firenze (ASF),

Florence, Italy

\section{Dörr}

Department of Internal Medicine B,

University Medicine Greifswald,

Greifswald, Germany

N. Franceschini

Department of Epidemiology, University of North Carolina, Chapel Hill, NC, USA

V. Gudnason • A. V. Smith

Icelandic Heart Association,

Kópavogur, Iceland

V. Gudnason · A. V. Smith

University of Iceland,

Reykjavik, Iceland evidence exists for a highly important role for HSF1 in longevity. Reduced activity of HSF1 in C. elegans leads to a rapid aging phenotype with a markedly reduced lifespan of $60 \%$ (Garigan et al. 2002). Conversely, animals with an additional HSF1 gene copy lived approximately $40 \%$ longer than normal (Hsu et al. 2003). A strong relationship was found between HSF 1 and DAF-16, which functions in the C. elegans insulin/IGF-1 signaling pathway (Hsu et al. 2003). Both genes were shown to function, at least in part, by increasing sHSP gene expression (Hsu et al. 2003).

We have tested 31 genes encoding all members of the HSP70, sHSP, and HSF families and assessed their association with all-cause mortality. To our knowledge, this is the first large-scale candidate gene study of these HSPs and their association to all-cause mortality to be performed.

\section{Methods}

Discovery study

Our discovery cohort was the Rotterdam study (RS1). $\mathrm{RS} 1$ is a population-based cohort study that investigates

Y. Liu

Department of Biostatistical Sciences, Wake

Forest University School of Medicine,

Winston-Salem, NC, USA

J. M. Murabito

Section of General Internal Medicine, Department of

Medicine, Boston University School of Medicine,

72 E. Concord Street,

Boston, MA 02118, USA

A. B. Newman

Graduate School of Public Health, University of Pittsburgh, Pittsburgh, PA, USA

\author{
B. A. Oostra \\ Department of Clinical Genetics, Erasmus Medical Center, \\ Rotterdam, The Netherlands \\ B. M. Psaty \\ Cardiovascular Health Research Unit, Departments of \\ Medicine, Epidemiology, and Health Services, \\ University of Washington, \\ Seattle, WA, USA \\ B. M. Psaty \\ Group Health Research Unit, Group Health Cooperative, \\ Seattle, WA, USA
}


the occurrence and determinants of diseases in the elderly (Hofman et al. 2011). Baseline examinations, including a detailed questionnaire, physical examination, and blood collection, were conducted between 1990 and 1993. The Medical Ethics Committee at Erasmus Medical Center approved the study protocol. All of the participants were followed for incident diseases through linkage to the general practitioner data base and record review by trained medical investigators. General practitioners' hospital records as well as death certificates were used for identification of deaths (allcause mortality) through January 1, 2009.

Genomic DNA was extracted from whole blood samples using standard methods (Miller et al. 1988). Genome-wide SNP genotyping was performed using Infinium II assay on the HumanHap550 Genotyping BeadChips (Illumina Inc, San Diego, USA). Approximately two million SNPs were imputed using release 22 HapMap CEU population as reference. The imputations were performed using MACH software (http:// www.sph.umich.edu/csg/abecasis/MACH/). The quality of imputations were checked by contrasting imputed and actual genotypes at 78,844 SNPs not present on Illumina $550 \mathrm{~K}$ for 437 individuals for whom these SNPs were directly typed using Affymetrix $500 \mathrm{~K}$. Using the "best guess" genotype for imputed SNPs the concordance rate was $99 \%$ for SNPs with $R^{2}$ (ratio of the variance of imputed genotypes to the binomial variance) quality measure greater than 0.9 ; concordance was still over $90 \%$ (94\%) when $R^{2}$ was between 0.5 and 0.9 . The GWAS of all-cause mortality has been analyzed and is published elsewhere (Walter et al. 2011).

For the study of HSPs presented here, a total of 4,430 SNPs in 31 genes were initially selected for the association test on the basis of the following criteria: (1) position within the genes of interest with a margin of $100 \mathrm{~kb}$ on each side of the genes according to NCBI build 36.3; (2) $p$ value for Hardy-Weinberg equilibrium test $\geq 0.0001$; and (3) call rate $\geq 95 \%$. For further analysis and selection of SNPs for replication analysis, only SNPs with an $R^{2}$ higher than 0.8 and a minor allele frequency higher than 0.05 were selected.

Analyses

We performed single SNP analyses using ProbABEL (Aulchenko et al. 2010). We used survival analysis (semi-parametric Cox proportional hazard model), adjusted for age at DNA blood collection and for sex, to model continuous time to death in individuals that were older than 55 years at baseline. To calculate empirical significance for SNPs, permutations were performed per region of interest (ROI) (Churchill and Doerge 1994; Fisher 1935). Briefly, the empirical distribution of the region-wide maximum of the test statistic under the null was obtained in 10,000 replications. To estimate empirical significance, each observed test statistic was compared with null statistics obtained empirically and the $p$ value was estimated as the proportion of replicas generating the test statistics greater than or equal to the observed statistic. The permutation analysis keeps the original genotypes for each individual, but randomly allocates the phenotypes for each consecutive permutation. Therefore, the linkage disequilibrium structure of genes is not broken up. We did not perform any additional correction for the number of ROIs after permutations as we used the permutation analysis to significantly reduce the number of SNPs to be selected for validation of the effect of the SNP. For each suggestively associated ROI $\left(p_{\text {permuted }}<0.10\right)$, we next selected the "truly associated" SNPs in a backward stepwise survival analysis until only nominally significant SNPs remained in the model. These independently associated SNPs were then followed up in eight independent cohorts. As effect estimates are expected to be small, a strict replication based on the $p$ value and hazard ratio (HR) observed in individual replication studies, might be difficult to achieve due to power issues. Therefore, we evaluated whether a SNP was showing a HR in the same direction in all cohorts, i.e., whether findings were consistent over the various cohorts. Similar to genome-wide association studies, we performed a joint meta-analysis of the discovery and the replication samples and tested whether the joint $p$ value was significant using a Bonferroni correction for the number of SNPs validated in the replication phase.

We used four studies that are part of the Cohorts for Heart and Aging Research in Genomic Epidemiology (CHARGE) consortium (Psaty et al. 2009) plus an additional four associated cohorts to evaluate whether findings were consistent. The studies included in this replication are: Cardiovascular Health Study (CHS); Framingham Heart Study (FHS); Atherosclerosis Risk Communities Study (ARIC); Age, Gene/Environment Susceptibility-Reykjavik Study (AGES); Health, Aging and Body Composition (HABC); Baltimore Longitudinal Study of Ageing (BLSA); InCHIANTI 
(ICH); and Study of Health in Pomerania (SHIP). All studies are longitudinal population-based studies periodically assessing the health and vital status of their participants. All participants included in this analysis were at least 55 years of age at the time of blood draw for DNA and provided written informed consent. Detailed information on the replication studies can be found in the supplement.

\section{Results}

General characteristics of the discovery cohort as well as the eight replication cohorts are shown in Table 1. In the discovery cohort, there were 3,174 deaths with a mean age at death of 83.2 and mean follow-up of 12.5 years. In RS1 and replications combined, there were 8,444 deaths with a mean age at death of 81.1. The mean follow-up time ranged from 5.2 to 15.7 years. A summary of all SNPs tested in the HSP genes in RS1 can be found in Supplementary Table 1. Three HSP70 genes are located head to head on chromosome 6 and are taken as one ROI with 148 SNPs (HSPA1). Similarly, two sHSP genes on chromosome 11 with 66 SNPs were located nearby each other and taken as one ROI (ROIchr11). Also of note is that the HSPs are currently undergoing a change in nomenclature (Kampinga et al. 2009). Supplementary Table 1 provides both the official gene names and the gene names according to the new nomenclature. Here, we will use the aliases from the new nomenclature.

Figure $1 \mathrm{a}-\mathrm{d}$ illustrate the observed versus the expected $\mathrm{chi}^{2}$ of the SNPs tested in the different HSP gene families in RS1. The plots show an excess of low $p$ values for tested SNPs in SHSP (1b) and HSF (1c) but not for HSP70 (1a). Supplementary Fig. 1 shows an overview of the $p$ values in all HSP70, sHSP, and HSF genes tested in RS1. After adjusting for multiple testing by permutation analysis, three genes showed evidence for association to mortality in RS1. These genes encode HSP70 member HSPA8, sHSP member $H S P B 1$, and HSF member HSF2. Table 2 shows the three SNPs that were selected for replication. In the replication phase, only one SNP reached a Bonferroni adjusted $p$ value for significance $(0.05 / 3=0.017)$. Figure 2a shows the Forest plot of the meta-analysis of HSF 2 rs1416733. The direction of effect was consistent across populations with only one study (HABC) showing an opposite HR. The summary HR for this SNP was 0.95 (95\% CI $0.92-0.98 ; p=0.003$ ) for the A allele. When excluding the discovery cohort from the meta-analysis, the HR remained virtually unchanged (0.97: CI 0.93-1.00). In Fig. 2b, a regional plot of all SNPs tested in HSF2 from the original RS1 cohort can be found. In the plot, we can see that rs1416733 is located $11.7 \mathrm{~Kb}$ from the $5^{\prime}$ region of the HSF2 gene, with no other genes nearby.

Table 1 General characteristics

\begin{tabular}{|c|c|c|c|c|c|c|}
\hline Study & $N$ & $N$ deceased & $\begin{array}{l}\text { Mean age at } \\
\text { Baseline }( \pm \mathrm{SD})\end{array}$ & $\begin{array}{l}\text { Mean age at } \\
\text { death }( \pm \mathrm{SD})\end{array}$ & $\begin{array}{l}\text { Sex, } \% \\
\text { female }\end{array}$ & $\begin{array}{l}\text { Mean follow-up } \\
\text { time in years }( \pm \mathrm{SD})\end{array}$ \\
\hline Rotterdam study (RS1) & 5974 & 3,174 & $69.4(9.1)$ & $83.2(8.3)$ & 59 & $12.5(5.2)$ \\
\hline Cardiovascular health study (CHS) & 3,267 & 1,718 & $72.3(5.4)$ & $83.4(6.3)$ & 61 & $12.3(4.2)$ \\
\hline Framingham heart study (FHS) & 3,136 & 654 & $70.0(10.2)$ & $83.0(9.3)$ & 56 & $6.0(2.4)$ \\
\hline $\begin{array}{l}\text { Atherosclerosis risk communities } \\
\text { study (ARIC) }\end{array}$ & 4,511 & 1,108 & $59.4(2.9)$ & $71.3(5.4)$ & 50 & $15.7(3.7)$ \\
\hline $\begin{array}{l}\text { Age, gene/environment susceptibility- } \\
\text { Reykjavik study (AGES) }\end{array}$ & 3,219 & 558 & $76.4(5.5)$ & $79.3(5.9)$ & 58 & $5.2(1.3)$ \\
\hline $\begin{array}{l}\text { The health, aging and body } \\
\text { composition (HABC) }\end{array}$ & 1,661 & 460 & $73.8(2.8)$ & $80.4(3.7)$ & 47 & $8.2(2.3)$ \\
\hline $\begin{array}{l}\text { Baltimore longitudinal study } \\
\text { of ageing (BLSA) }\end{array}$ & 620 & 183 & $62.0(8.8)$ & $86.8(8.0)$ & 41 & $15.7(8.2)$ \\
\hline Invecchiare nel Chianti (InCHIANTI) & 902 & 183 & $72.5(7.7)$ & $85.4(7.9)$ & 56 & $5.9(0.9)$ \\
\hline Study of health in Pomerania (SHIP) & 1,717 & 406 & $66.4(7.2)$ & $76.9(7.2)$ & 47 & $9.2(2.4)$ \\
\hline TOTAL & 25,007 & 8,444 & $69.0(8.9)$ & $81.1(8.4)$ & 55 & $10.6(5.4)$ \\
\hline
\end{tabular}


A.

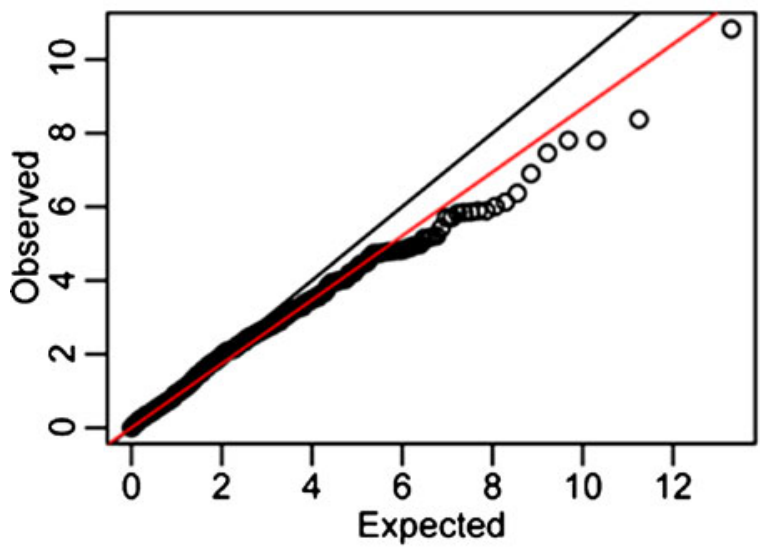

B.

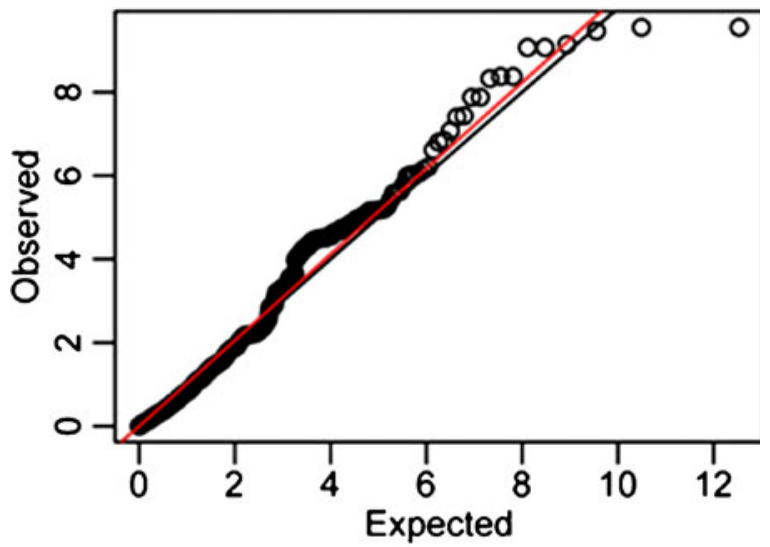

C.

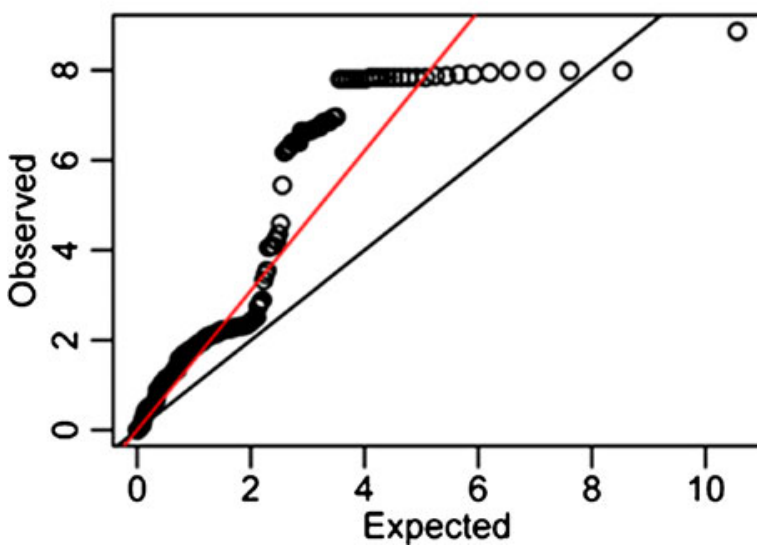

Fig. 1 Observed versus expected $p$ value plot for the SNPs tested in the Rotterdam study $\left(\mathrm{chi}^{2}\right.$ are given at the $\mathrm{x}$-axis and y-axis). a HSP70; b sHSP; c HSF. Black line depicts the expected findings; red line depicts the observed ones

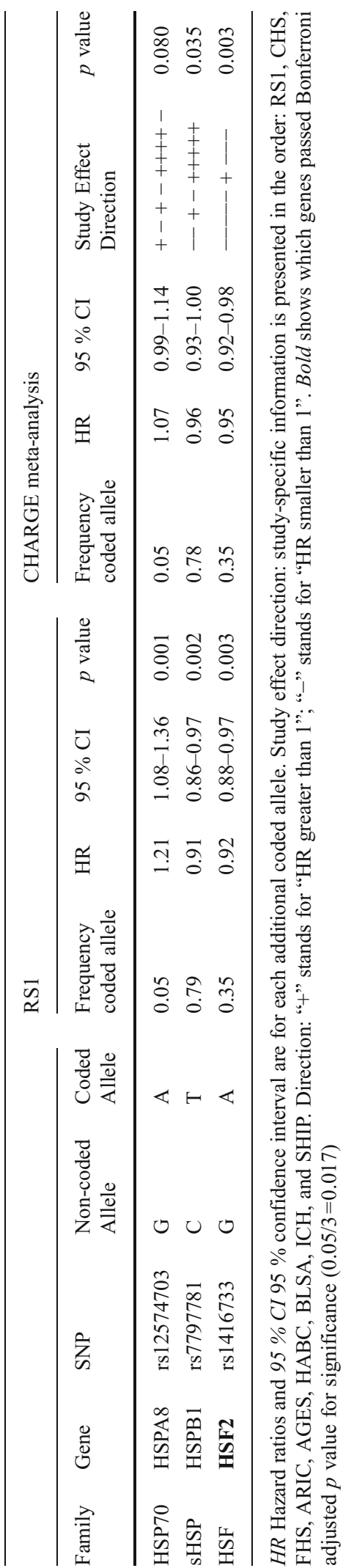


Fig. 2 The meta-analysis of the HSF2 rs1416733 SNP

in the nine population cohorts. a Forrest plot. b Regional plot in RS1

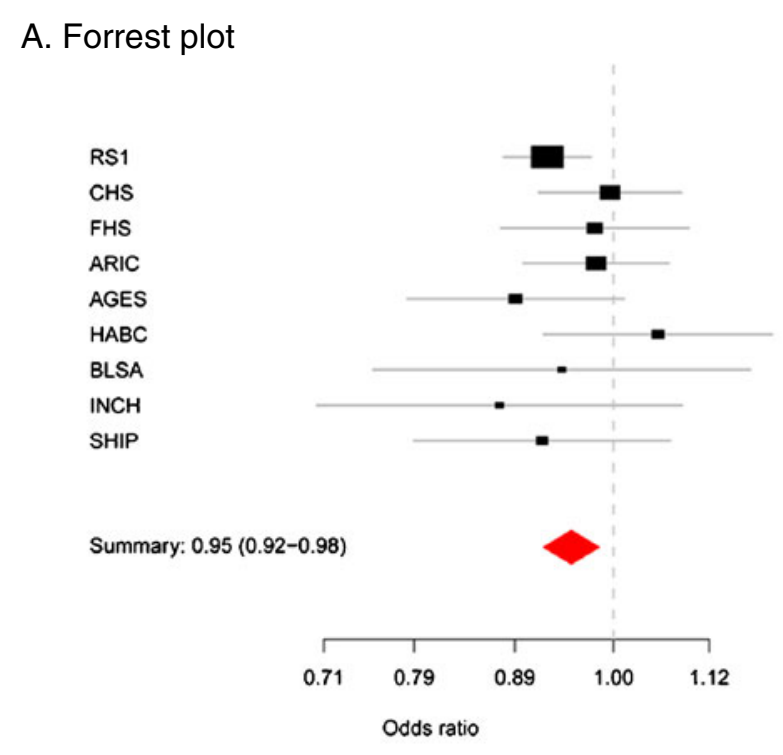

B. Regional plot in RS1

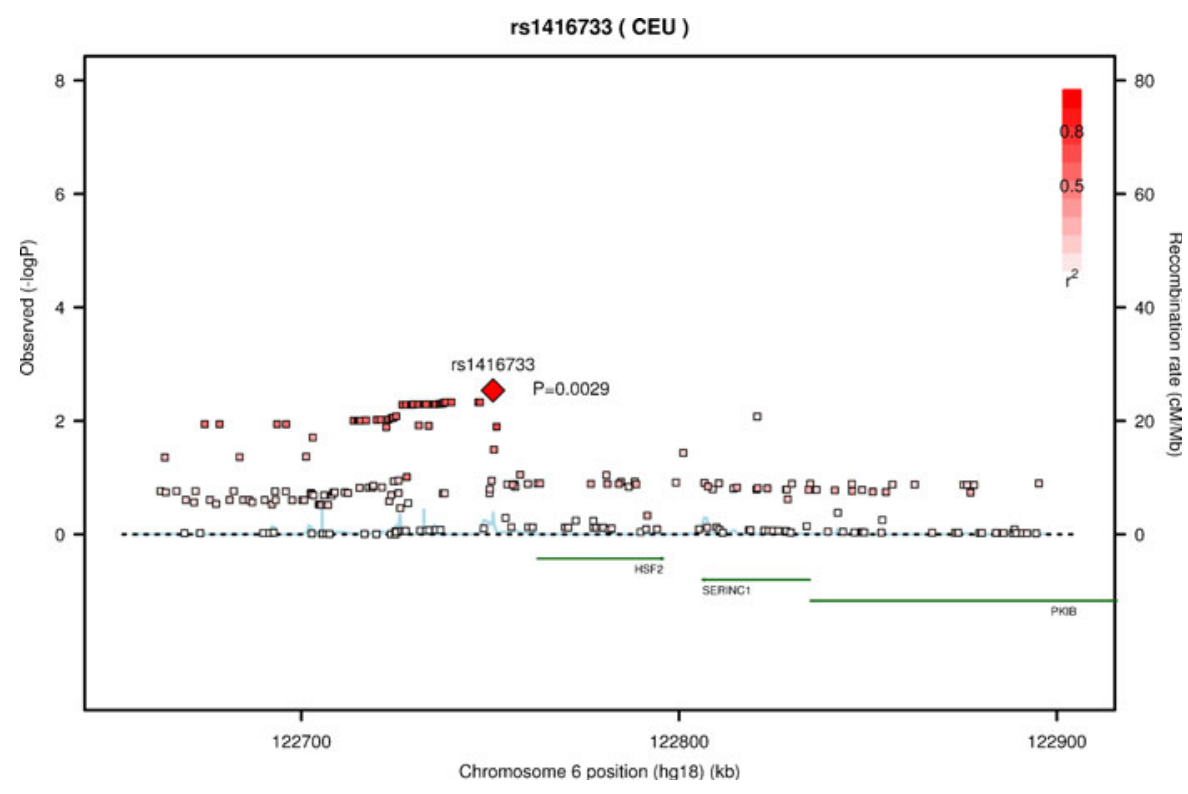

\section{Discussion}

In our study, we found a significant association between HSF 2 and all-cause mortality. The top associated variant, rs1416733, is located $11.7 \mathrm{~Kb}$ from the $5^{\prime}$ region of the HSF 2 gene on chromosome 6 and is a known ciseQTL for HSF2 (Zeller et al. 2010). Each additional copy of the A allele for SNP rs1416733 increased lifespan with a HR of 0.95 in a meta-analysis of nine independent cohort studies. This effect was consistent in direction in eight out of nine cohorts.
The HSF family, like most HSP families, is a highly conserved family across species, indicating a vital role for the survival of the respective organism (Liu et al. 1997). Unlike many other HSP families, there is virtually no redundancy in the HSF family, with HSF1 as the most crucial family member (Akerfelt et al. 2010). The importance of HSF1 is advocated strongly by the large effects of genetic mutations in this gene on longevity in C. elegans (Garigan et al. 2002; Hsu et al. 2003). These large effects are not anticipated in human research, which could explain why we find no 
evidence for association of SNPs in HSF1 with allcause mortality (Walter et al. 2011). HSF2 is less known in longevity research. It has previously been mainly described for its role as a development- and differentiation-specific factor (Kallio et al. 2002; Wang et al. 2003). The role of HSF2 in later life has remained unknown for a long time (Wu 1995). Recently, evidence is emerging to suggest that HSF2 modulates HSF1 activity (Akerfelt et al. 2010). It has been shown that HSF2 activation leads to activation of HSF1, revealing a functional interdependency (Sandqvist et al. 2009). It has been proposed that heterotrimerization of HSF1 and HSF2 integrates transcriptional activation in response to distinct stress and developmental stimuli (Sandqvist et al. 2009). Additionally, though HSF2 was never considered to be heat-inducible, a recent study shows that a mild heatshock in the physiological range does activate HSF2 and has a significant impact on the proteostasis of the cell (Shinkawa et al. 2011).

We found no evidence for association of HSP70 with all-cause mortality. HSP70 is the only HSP family for which SNPs in a couple of genes have been studied for longevity in humans previously. However, these studies only studied two or three SNPs and only in the heatinducible members of HSP70, namely HSPA1A, $H S P A 1 B$, and HSPAIL, all located on chromosome 6 (Altomare et al. 2003; Ross et al. 2003; Terry et al. 2006). In our study, no association was found for these three genes with longevity. We add a more thorough investigation of these genes and the other HSP70 genes by extensively covering common variance.

The sHSPs have been named most often in animal studies for their relationship with longevity (Morrow et al. 2004a; Morrow et al. 2004b; Walker et al. 2001). However, we find no significant associations for single SNPs in these genes. Off course, what we find in animal studies does not always translate well to humans. For example, though genetic variations in IGF-1 signaling have been found in humans, they do not have nearly as strong effects on longevity as in animal models (Kuningas et al. 2008). Another study has found that mutations in HSF1 lead to upregulated sHSP expression in C. elegans (Hsu et al. 2003). We cannot exclude that genetic variation in $H S F 2$ activates a similar mechanism in humans through its effect on HSF1.

Our study has a major advantage since the discovery cohort - the Rotterdam Study - is a large, population- based study. Further, the eight replication cohorts are also relatively large, established population-based epidemiological cohorts. A limitation in the interpretation of our data is that our findings were significant in the meta-analysis but did not reach significance in the individual cohorts except for the RS1 cohort; however, a total of eight out of nine studies showed an effect in the same direction for $H S F 2$. This could be explained by the markedly smaller percentage of deaths in most replication cohorts (except CHS) compared to the discovery cohort. The number of deceased is critical for the statistical power of the study. Even though some of these studies had a longer mean follow-up time (ARIC and BLSA), the population in these studies were on average younger at baseline compared to RS1, which explains the fewer number of deaths and leaves the individual replication studies underpowered to identify rs1416733.

Until now, no large-scale studies have been performed investigating the role of HSP70, sHSP, or HSF genes in all-cause mortality in humans. In our candidate gene study in nine population-based cohorts, we found significant evidence suggesting that genetic variants in $H S F 2$ are associated with all-cause mortality. Combining these data with those of earlier functional studies, in particular in C. elegans, makes it likely that $H S F 2$ plays a role in human all-cause mortality.

\section{Acknowledgments}

Rotterdam study: The Rotterdam Study is supported by Netherlands Genomics Initiative/Netherlands Consortium for Healthy Aging (050-060-810); Netherlands Organisation for Scientific Research (NWO) (904-61-090, 904-61-193, 480-04004, 400-05-717, SPI 56-464-1419, 175.010.2005.011 and 91103-012); Netspar-Living longer for a good health.

Cardiovascular health study: The CHS research reported in this article was supported by contract numbers N01-HC-85079 through N01-HC-85086, N01-HC-35129, N01 HC-15103, N01 HC-55222, N01-HC-75150, N01-HC-45133, grant numbers U01 HL080295, and R01 HL087652 from the National Heart, Lung, and Blood Institute, the National Institute of Aging R01 AG031890 with additional contribution from the National Institute of Neurological Disorders and Stroke. A full list of principal CHS investigators and institutions can be found at http:// www.chs-nhlbi.org/pi.htm. DNA handling and genotyping was supported in part by National Center for Research Resources grant M01-RR00425 to the Cedars-Sinai General Clinical Research Center Genotyping core and National Institute of Diabetes and Digestive and Kidney Diseases grant DK063491 to the Southern California Diabetes Endocrinology Research Center. 
Framingham heart study: The Framingham study phenotype-genotype analyses were supported by the National Institute of Aging grant number R01AG029451 (PI: JMM). The Framingham Heart Study of the National Heart Lung and Blood Institute of the National Institutes of Health and Boston University School of Medicine were supported by the National Heart, Lung and Blood Institute's Framingham Heart Study Contract No. N01-HC-25195 and its contract with Affymetrix, Inc for genotyping services (Contract No. N02-HL-6-4278). Analyses reflect intellectual input and resource development from the Framingham Heart Study investigators participating in the SNP Health Association Resource (SHARe) project. A portion of this research was conducted using the Linux Cluster for Genetic Analysis (LinGA-II) funded by the Robert Dawson Evans Endowment of the Department of Medicine at Boston University School of Medicine and Boston Medical Center. This research was additionally supported by the following grants: AG033193, AG081220, NS17950, P30AG013846, 1R01AG028321, and AR/AG 41398.

\begin{abstract}
Atherosclerosis risk in communities study: The Atherosclerosis Risk in Communities Study is carried out as a collaborative study supported by National Heart, Lung, and Blood Institute contracts N01-HC-55015, N01-HC-55016, N01-HC-55018, N01HC-55019, N01-HC-55020, N01-HC-55021, and N01-HC55022. The authors thank the staff and participants of the ARIC study for their important contributions.
\end{abstract}

Age, gene/environment susceptibility-Reykjavik study: The Age, Gene/Environment Susceptibility-Reykjavik Study is funded by NIH contract N01-AG-12100, the NIA Intramural Research Program, Hjartavernd (the Icelandic Heart Association), and the Althingi (the Icelandic Parliament). Genotyping was conducted at the NIA IRP Laboratory of Neurogenetics.

Invecchiare nel Chianti: The InCHIANTI study baseline (1998-2000) was supported as a "targeted project" (ICS110.1/ RF97.71) by the Italian Ministry of Health and in part by the U.S. National Institute on Aging (Contracts: 263 MD 9164 and 263 MD 821336).

Baltimore longitudinal study of ageing: The BLSA was supported in part by the Intramural Research Program of the $\mathrm{NIH}$, National Institute on Aging. A portion of that support was through a R\&D contract with MedStar Research Institute.

Health, aging and body composition: This research is supported in part by the Intramural Research Program of the NIH, National Institute on Aging. This research was supported by NIA contracts N01AG62101, N01AG62103, N01AG62106, and NIA grant 1R03AG032498-01. The genome-wide association study was funded by NIA grant 1R01AG032098-01A1 to Wake Forest University Health Sciences and genotyping services were provided by the Center for Inherited Disease Research (CIDR). CIDR is fully funded through a federal contract from the National Institutes of Health to The Johns Hopkins University, contract number HHSN268200782096C.
Study of health in Pomerania: SHIP is part of the Community Medicine Research net of the University of Greifswald, Germany, which is funded by the Federal Ministry of Education and Research (grants no. 01ZZ9603, 01ZZ0103, and 01ZZ0403), the Ministry of Cultural Affairs as well as the Social Ministry of the Federal State of Mecklenburg-West Pomerania. Genome-wide data have been supported by the Federal Ministry of Education and Research (grant no. 03ZIK012) and a joint grant from Siemens Healthcare, Erlangen, Germany and the Federal State of Mecklenburg- West Pomerania. The University of Greifswald is a member of the "Center of Knowledge Interchange" program of the Siemens AG.

Open Access This article is distributed under the terms of the Creative Commons Attribution License which permits any use, distribution, and reproduction in any medium, provided the original author(s) and the source are credited.

\section{References}

Akerfelt M, Morimoto RI, Sistonen L (2010) Heat shock factors: integrators of cell stress, development and lifespan. Nat Rev Mol Cell Biol 11(8):545-555. doi:10.1038/nrm2938

Altomare K, Greco V, Bellizzi D, Berardelli M, Dato S, DeRango F, Garasto S, Rose G, Feraco E, Mari V, Passarino G, Franceschi C, De Benedictis G (2003) The allele (A)(-110) in the promoter region of the HSP70-1 gene is unfavorable to longevity in women. Biogerontology 4(4):215-220

Aulchenko YS, Struchalin MV, van Duijn CM (2010) ProbABEL package for genome-wide association analysis of imputed data. BMC Bioinformatics 11:134. doi:10.1186/1471-210511-134

Churchill GA, Doerge RW (1994) Empirical threshold values for quantitative trait mapping. Genetics 138(3):963-971

Cypser J, Johnson TE (2001) Hormesis extends the correlation between stress resistance and life span in long-lived mutants of Caenorhabditis elegans. Hum Exp Toxicol 20 (6):295-296, discussion 319-220

Cypser JR, Johnson TE (2002) Multiple stressors in Caenorhabditis elegans induce stress hormesis and extended longevity. $\mathrm{J}$ Gerontol A Biol Sci Med Sci 57(3):B109-114

Fisher R (1935) The design of experiments, vol 3, 3rd edn. Oliver \& Boyd Ltd., London

Garigan D, Hsu AL, Fraser AG, Kamath RS, Ahringer J, Kenyon C (2002) Genetic analysis of tissue aging in Caenorhabditis elegans: a role for heat-shock factor and bacterial proliferation. Genetics 161(3):1101-1112

Garrido C, Brunet M, Didelot C, Zermati Y, Schmitt E, Kroemer G (2006) Heat shock proteins 27 and 70: anti-apoptotic proteins with tumorigenic properties. Cell Cycle 5(22):2592-2601

Hercus MJ, Loeschcke V, Rattan SI (2003) Lifespan extension of Drosophila melanogaster through hormesis by repeated mild heat stress. Biogerontology 4(3):149-156

Hofman A, van Duijn CM, Franco OH, Ikram MA, Janssen HL, Klaver CC, Kuipers EJ, Nijsten TE, Stricker BH, Tiemeier H, Uitterlinden AG, Vernooij MW, Witteman JC (2011) The Rotterdam study: 2012 objectives and design update. Eur J Epidemiol 26(8):657-686. doi:10.1007/s10654-0119610-5 
Hsu AL, Murphy CT, Kenyon C (2003) Regulation of aging and age-related disease by DAF-16 and heat-shock factor. Science 300(5622):1142-1145. doi:10.1126/science.1083701300/ $5622 / 1142$

Kallio M, Chang Y, Manuel M, Alastalo TP, Rallu M, Gitton Y, Pirkkala L, Loones MT, Paslaru L, Larney S, Hiard S, Morange M, Sistonen L, Mezger V (2002) Brain abnormalities, defective meiotic chromosome synapsis and female subfertility in HSF2 null mice. EMBO J 21 (11):2591-2601. doi:10.1093/emboj/21.11.2591

Kampinga HH, Hageman J, Vos MJ, Kubota H, Tanguay RM, Bruford EA, Cheetham ME, Chen B, Hightower LE (2009) Guidelines for the nomenclature of the human heat shock proteins. Cell Stress Chaperones 14(1):105-111. doi:10.1007/s12192-008-0068-7

Kuningas M, Mooijaart SP, van Heemst D, Zwaan BJ, Slagboom PE, Westendorp RG (2008) Genes encoding longevity: from model organisms to humans. Aging Cell 7(2):270-280. doi:10.1111/j.1474-9726.2008.00366.x

Le Bourg E, Valenti P, Lucchetta P, Payre F (2001) Effects of mild heat shocks at young age on aging and longevity in Drosophila melanogaster. Biogerontology 2(3):155-164

Link CD, Cypser JR, Johnson CJ, Johnson TE (1999) Direct observation of stress response in Caenorhabditis elegans using a reporter transgene. Cell Stress Chaperones 4(4):235-242

Lithgow GJ, White TM, Melov S, Johnson TE (1995) Thermotolerance and extended life-span conferred by single-gene mutations and induced by thermal stress. Proc Natl Acad Sci USA 92(16):7540-7544

Liu XD, Liu PC, Santoro N, Thiele DJ (1997) Conservation of a stress response: human heat shock transcription factors functionally substitute for yeast HSF. EMBO J 16(21):64666477. doi:10.1093/emboj/16.21.6466

Miller SA, Dykes DD, Polesky HF (1988) A simple salting out procedure for extracting DNA from human nucleated cells. Nucleic Acids Res 16(3):1215

Morrow G, Battistini S, Zhang P, Tanguay RM (2004a) Decreased lifespan in the absence of expression of the mitochondrial small heat shock protein Hsp22 in Drosophila. J Biol Chem 279(42):43382-43385. doi:10.1074/ jbc.C400357200C400357200

Morrow G, Samson M, Michaud S, Tanguay RM (2004b) Overexpression of the small mitochondrial Hsp22 extends Drosophila life span and increases resistance to oxidative stress. FASEB J 18(3):598-599. doi:10.1096/fj.03-0860fje030860fje

Psaty BM, O'Donnell CJ, Gudnason V, Lunetta KL, Folsom AR, Rotter JI, Uitterlinden AG, Harris TB, Witteman JC, Boerwinkle E, Consortium C (2009) Cohorts for heart and aging research in genomic epidemiology (CHARGE) consortium: design of prospective meta-analyses of genome-wide association studies from 5 cohorts. Circ Cardiovasc Genet 2(1):73-80

Rattan SI (1998) Repeated mild heat shock delays ageing in cultured human skin fibroblasts. Biochem Mol Biol Int 45(4):753-759

Ritossa F (1962) A new puffing pattern induced by heat shock and DNP in Drosophila. Cell Mol Life Sci 18:571

Ritossa F (1996) Discovery of the heat shock response. Cell Stress Chaperones 1(2):97-98

Ross OA, Curran MD, Crum KA, Rea IM, Barnett YA, Middleton D (2003) Increased frequency of the $2437 \mathrm{~T}$ allele of the heat shock protein 70-Hom gene in an aged Irish population. Exp Gerontol 38(5):561-565

Sandqvist A, Bjork JK, Akerfelt M, Chitikova Z, Grichine A, Vourc'h C, Jolly C, Salminen TA, Nymalm Y, Sistonen L (2009) Heterotrimerization of heat-shock factors 1 and 2 provides a transcriptional switch in response to distinct stimuli. Mol Biol Cell 20(5):1340-1347. doi:10.1091/ mbc.E08-08-0864

Shama S, Lai CY, Antoniazzi JM, Jiang JC, Jazwinski SM (1998) Heat stress-induced life span extension in yeast. Exp Cell Res 245(2):379-388. doi:10.1006/excr.1998.4279

Shinkawa T, Tan K, Fujimoto M, Hayashida N, Yamamoto K, Takaki E, Takii R, Prakasam R, Inouye S, Mezger V, Nakai A (2011) Heat shock factor 2 is required for maintaining proteostasis against febrile-range thermal stress and polyglutamine aggregation. Mol Biol Cell 22(19):3571-3583. doi:10.1091/mbc.E11-04-0330

Terry DF, Wyszynski DF, Nolan VG, Atzmon G, Schoenhofen EA, Pennington JY, Andersen SL, Wilcox MA, Farrer LA, Barzilai N, Baldwin CT, Asea A (2006) Serum heat shock protein 70 level as a biomarker of exceptional longevity. Mech Ageing Dev 127(11):862-868. doi:10.1016/j.mad.2006.08.007

Walker GA, White TM, McColl G, Jenkins NL, Babich S, Candido EP, Johnson TE, Lithgow GJ (2001) Heat shock protein accumulation is upregulated in a long-lived mutant of Caenorhabditis elegans. J Gerontol A Biol Sci Med Sci 56(7):B281-287

Walter S, Atzmon G, Demerath EW, Garcia ME, Kaplan RC, Kumari M, Lunetta KL, Milaneschi Y, Tanaka T, Tranah GJ, Volker U, Yu L, Arnold A, Benjamin EJ, Biffar R, Buchman AS, Boerwinkle E, Couper D, De Jager PL, Evans DA, Harris TB, Hoffmann W, Hofman A, Karasik D, Kiel DP, Kocher T, Kuningas M, Launer LJ, Lohman KK, Lutsey PL, Mackenbach J, Marciante K, Psaty BM, Reiman EM, Rotter JI, Seshadri S, Shardell MD, Smith AV, van Duijn C, Walston J, Zillikens MC, Bandinelli S, Baumeister SE, Bennett DA, Ferrucci L, Gudnason V, Kivimaki M, Liu Y, Murabito JM, Newman AB, Tiemeier H, Franceschini N (2011) A genomewide association study of aging. Neurobiol Aging 32(11):2109. doi:10.1016/j.neurobiolaging.2011.05.026

Wang G, Zhang J, Moskophidis D, Mivechi NF (2003) Targeted disruption of the heat shock transcription factor (hsf)-2 gene results in increased embryonic lethality, neuronal defects, and reduced spermatogenesis. Genesis 36(1):4861. doi:10.1002/gene. 10200

Wu C (1995) Heat shock transcription factors: structure and regulation. Annu Rev Cell Dev Biol 11:441-469. doi:10.1146/annurev.cb.11.110195.002301

Yokoyama K, Fukumoto K, Murakami T, Harada S, Hosono R, Wadhwa R, Mitsui Y, Ohkuma S (2002) Extended longevity of Caenorhabditis elegans by knocking in extra copies of hsp70F, a homolog of mot-2 (mortalin)/mthsp70/Grp75. FEBS Lett 516(1-3):53-57

Zeller T, Wild P, Szymczak S, Rotival M, Schillert A, Castagne R, Maouche S, Germain M, Lackner K, Rossmann H, Eleftheriadis M, Sinning CR, Schnabel RB, Lubos E, Mennerich D, Rust W, Perret C, Proust C, Nicaud V, Loscalzo J, Hubner N, Tregouet D, Munzel T, Ziegler A, Tiret L, Blankenberg S, Cambien F (2010) Genetics and beyond - the transcriptome of human monocytes and disease susceptibility. PLoS One 5(5):e10693. doi:10.1371/ journal.pone.0010693 